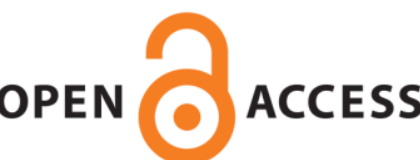

OPEN ACCESS

UWS Academic Portal

\title{
Characterisation of $\mathrm{Cu} 2 \mathrm{O}, \mathrm{Cu} 403$, and $\mathrm{CuO}$ mixed phase thin films produced by microwave-activated reactive sputtering
}

Alajlani, Yahya; Placido, Francis; Barlow, Anders; Chu, Hin On; Song, Shigeng; Rahman, Saeed Ur; De Bold, Robert; Gibson, Desmond

Published in:

Vacuum

DOI:

10.1016/j.vacuum.2017.08.005

Published: 01/10/2017

Document Version

Peer reviewed version

Link to publication on the UWS Academic Portal

Citation for published version (APA):

Alajlani, Y., Placido, F., Barlow, A., Chu, H. O., Song, S., Rahman, S. U., De Bold, R., \& Gibson, D. (2017). Characterisation of $\mathrm{Cu} 2 \mathrm{O}, \mathrm{Cu} 4 \mathrm{O} 3$, and $\mathrm{CuO}$ mixed phase thin films produced by microwave-activated reactive sputtering. Vacuum, 144, 217-228. [144]. https://doi.org/10.1016/j.vacuum.2017.08.005

\section{General rights}

Copyright and moral rights for the publications made accessible in the UWS Academic Portal are retained by the authors and/or other copyright owners and it is a condition of accessing publications that users recognise and abide by the legal requirements associated with these rights.

Take down policy

If you believe that this document breaches copyright please contact pure@uws.ac.uk providing details, and we will remove access to the work immediately and investigate your claim. 


\title{
Characterisation of $\mathrm{Cu}_{2} \mathrm{O}, \mathrm{Cu}_{4} \mathrm{O}_{3}$, and $\mathrm{CuO}$ mixed phase thin films produced by microwave-activated reactive sputtering
}

\author{
Yahya Alajlani ${ }^{1,2}$, Frank Placido ${ }^{1}$, Anders Barlow $^{3}$, Hin On $\mathrm{Chu}^{1}$, Shigeng Song ${ }^{1}$, \\ Saeed Ur Rahman ${ }^{1}$, Robert De Bold ${ }^{4}$, Des Gibson ${ }^{1}$ \\ ${ }^{1}$ Scottish Universities Physics Alliance (SUPA), Institute of Thin Films, Sensors and Imaging, \\ University of the West of Scotland, Paisley, UK \\ ${ }^{2}$ Department of Physics, Faculty of Science, Jazan University, Jazan, Saudi Arabia \\ ${ }^{3}$ Centre for Materials and Surface Sciences (CMSS), Department of Chemistry and Physics, \\ La Trobe University, Melbourne, Victoria, Australia \\ ${ }^{4}$ Institute for Infrastructure and Environment, School of Engineering, University of \\ Edinburgh, Edinburgh, UK
}

Keywords: nanostructure; copper oxide; microwave-activated reactive sputtering; OJL model.

\section{Abstract}

Copper readily forms three oxides, $\mathrm{CuO}, \mathrm{Cu}_{4} \mathrm{O}_{3}$ and $\mathrm{Cu}_{2} \mathrm{O}$, widely recognised as the most promising p-type oxides because of their desirable optical and electrical properties and potential use in solar cells, transparent electronics as well as other specialised applications such as electrodes for rechargeable lithium batteries, catalysis and memristors. For largescale implementation of devices, magnetron sputtering is a practical method of producing metal oxides; however, sputtered copper oxides tend to form as a mixture of the oxides, with $\mathrm{Cu}_{2} \mathrm{O}$ being particularly difficult to produce reliably in pure form. Here, nanostructured 
thin films of copper oxides were prepared by a variation on reactive sputtering known as microwave-activated reactive sputtering under various rates of oxygen flow. Microwaveactivated reactive sputtering was shown to be a suitable technique for the inexpensive production of large areas of copper oxide thin films at near room temperature, facilitating deposition on a wide variety of substrates including polymers. Furthermore, it was demonstrated that the sputtered films develop through $\mathrm{CuO}, \mathrm{Cu} 4 \mathrm{O} 3$ and $\mathrm{Cu} 2 \mathrm{O}$ mixed phases as oxygen flow rate is increased. The preparation of a given stoichiometry for a particular application can be achieved by varying the flow rate of oxygen during the microwave-activated reactive sputtering process.

\section{Introduction}

The facile and inexpensive production of large areas of copper oxide thin films is desirable because of the very many potential applications. For example, it has been noted that the development of new applications of transparent electronics such as displays and solar cells with improved efficiency and reduced costs requires inexpensive materials for both n-type and p-type semiconductors along with lower energy production methods $[1,2]$. One of the main factors for the optimal use of copper oxides in particular applications is the control of the deposition process [3].

Cuprous oxide $\left(\mathrm{Cu}_{2} \mathrm{O}\right)$ and cupric oxide $(\mathrm{CuO})$, are attractive material choices for transparent electronics because copper is an inexpensive and abundant metal, and the oxides are natural p-type semiconductors with a direct band gap $[4,5,6]$. Both oxides may be useful for solar cells, although $\mathrm{CuO}$ has higher absorbance over a wider wavelength range than $\mathrm{Cu}_{2} \mathrm{O}$. On the other hand, for transparent electronics $\mathrm{Cu}_{2} \mathrm{O}$ has the advantage of greater transparency in the visible spectrum. The two oxides have distinctly different properties, 
with $\mathrm{Cu}_{2} \mathrm{O}$ being a yellow/red colour and $\mathrm{CuO}$ being a much darker brown/black colour in thin film form due to differences in the band gap and dispersion of the extinction coefficient over the visible/near infrared region of the spectrum [7]. Bandgaps in the range of 2.0-2.6 eV have been reported for $\mathrm{Cu}_{2} \mathrm{O}$ films [8], while nominally $\mathrm{CuO}$ films are typically in the lower range of 1.2-1.6 eV. [9]. The rather wide ranges reported for material and electrical properties reflect the fact that films produced by many of the proposed fabrication methods invariably contain varying mixtures of copper and copper oxide phases and are rarely pure forms of the oxides. This was demonstrated by Drobny \& Pulfrey [10], who found that reactive sputtering of copper oxide at higher oxygen partial pressures deposited more oxygen rich phases: $\mathrm{Cu}_{2} \mathrm{O}+\mathrm{Cu}$ at lower partial pressures, then $\mathrm{Cu}_{2} \mathrm{O}$ only, then $\mathrm{Cu}_{2} \mathrm{O}+\mathrm{CuO}$, and then finally $\mathrm{CuO}$ only at higher partial pressures.

However, since the early 2000s, it has been recognised that sputtering can in fact result in three oxides, with $\mathrm{Cu}_{4} \mathrm{O}_{3}$ being readily formed in addition to $\mathrm{CuO}$ and $\mathrm{Cu}_{2} \mathrm{O}$ and many earlier papers have failed to recognise this fact $[11,12] . \mathrm{Cu}_{4} \mathrm{O}_{3}$, known as paramelaconite in mineral form, is itself an interesting material, with potential use in catalysis $[13,14,15]$.

Ogwu, et al. [16], found that the sheet resistance of copper oxide thin films prepared by reactive magnetron sputtering increased with increased $\mathrm{O}_{2}$ flow rates during production. Therefore, it can be assumed that the presence of the more oxygen rich phases of copper oxide result in greater resistivity. Another very promising application area, for $\mathrm{Cu}_{2} \mathrm{O}$ thin films, is in memristors [17], the fourth passive circuit element (after resistors, capacitors and inductors) [18].

For the case of solar cells, it is usual to combine copper oxides with an n-type semiconductor film such as $\mathrm{ZnO}$ to fabricate $\mathrm{p}-\mathrm{n}$ heterojunctions $[19,20]$. Solar cells 
produced from copper oxide thin film have a theoretical efficiency of approximately $20 \%$ $[21,22]$; however, the best achieved efficiency so far is $6 \%$ [23].

There are numerous methods to produce copper oxide thin films, such as thermal oxidation [24], electrodeposition [9], chemical brightening [25], spraying [8], chemical vapour deposition [26], plasma evaporation [8], vacuum evaporation [27], molecular beam epitaxy [28], reactive sputtering $[10,9,25]$. All noted methods produce a mixture of phases of $\mathrm{Cu}$, $\mathrm{CuO}$, and $\mathrm{Cu}_{2} \mathrm{O}$ [29]. Balamurugan and Mehta [8] used the activated reactive evaporation technique and varied the nanocrystaline structure by varying the deposition parameters. The crystallinity was then analysed by $x$-ray diffractometer (XRD). The results showed that a single phase of $\mathrm{Cu}_{2} \mathrm{O}$ could be deposited at relatively low substrate temperatures using this technique.

Papadimitropoulos et al. [27] grew copper oxide layers by vacuum evaporation of copper onto silicon substrates in a nitrogen-oxygen atmosphere at temperatures between $185 \mathrm{C}$ and 450C. The Tauc-Lorentz model was successfully used to extract the refractive indices of the films. Li et al (2011) used a variation of sputtering known as HITUS and showed that single phase $\mathrm{Cu}_{2} \mathrm{O}$ could only be prepared within a very narrow range of deposition parameters.

The consensus of previous work is that copper oxides are potentially very useful materials but are particularly difficult to grow as a pure phase, free of contamination from other phases. While oxygen flow rate is the most important parameter, it appears that other process parameters also need careful control. This suggests that commercial applications requiring pure phases to be deposited reproducibly on large areas may be difficult to achieve, especially when cost and substrate factors require room temperature deposition without further processing steps such as annealing. 
This paper focuses on a scalable deposition method with proven commercial success, although not yet in widespread use, known as microwave-activated reactive sputtering (MARS). This method uses a pulsed DC power supply for sputtering plus a separate microwave source in a rotating drum configuration to achieve large area, room temperature deposition of a wide variety of metal oxides, nitrides and oxynitrides [30, 31]. Excellent control of deposition parameters allows deposition of high performance optical filters [32], including rugate-type filters, which require thick films to be grown with continuously variable refractive index $[33,34]$. Other advantages of this type of sputtering are that materials with very high melting points can be sputtered easily [35], whereas techniques such as evaporation can be difficult or impossible. Sputtered films usually have better substrate adhesion than evaporated films. Sputtering can also be undertaken at low temperatures in order to avoid damage to the substrate or other layers. Given that a target can be composed of a large amount of material and is maintenance free, the technique is well-suited for ultrahigh vacuum applications.

In this paper copper oxide films have been grown by MARS. With these films of $500 \mathrm{~nm}$ thickness it has not been possible to obtain quantitative compositional information with the techniques available but qualitative results from optical spectroscopy, XRD, Raman and XPS are presented in some detail. It is demonstrated that the sputtered films develop through $\mathrm{CuO}, \mathrm{Cu}_{4} \mathrm{O}_{3}$ and $\mathrm{Cu}_{2} \mathrm{O}$ mixed phases as oxygen flow rate is increased and can be successfully and reproducibly grown at room temperature. A pure form of $\mathrm{Cu}_{2} \mathrm{O}$ is only produced in a very narrow range of oxygen flow.

\section{Experimental Procedures}


In this work, a MARS system (MicroDyn ${ }^{8} 40000$ ) equipped with a $127 \mathrm{~mm} \times 380 \mathrm{~mm}$ highpurity copper target (>99.99\%), 10kW DC power supply (Advanced Energy MDX 10 with Spark-le V arc controller) and a $3 \mathrm{~kW}$ plasma source was used. This is a turbo-pumped system with an added Polycold 330 water trap and is capable of reaching an operating pressure of $\sim 10^{-6}$ torr in 15 minutes. The rotating drum in this model rotates about a horizontal axis at $60 \mathrm{revs} / \mathrm{min}$ and is capable of holding over $3600 \mathrm{~cm}^{2}$ of substrates. Mass flow controllers were used to control the flow rates of the gases, argon, and oxygen. Argon is admitted at the target position and oxygen at the microwave position. The separate microwave source offers several advantages in this system. Substrates passing the target receive a coating of a few nanometres of predominantly metal, which is then oxidized in the region of the microwave plasma, which is rich in atomic oxygen. The separation of deposition and oxidation greatly reduces the potential for poisoning of the target and arcing. The atomic oxygen is around 10 times more reactive than molecular oxygen and so uses lower oxygen flow rates, in addition the microwave plasma acts as a virtual anode, reducing the disappearing anode effect.

Here we use $30 \mathrm{~mm}$ by $12 \mathrm{~mm}$ by $1 \mathrm{~mm}$ thick glass substrates (standard microscope slides) and $20 \mathrm{~mm}$ diameter by $2 \mathrm{~mm}$ thickness circular silica substrates cleaned using an ultrasonic system (Optimal UCS40). Several experiments were undertaken where thin films were deposited on the substrates under conditions where the oxygen flow was varied from $10 \mathrm{sccm}$ to $28 \mathrm{sccm}$. In all cases reported here, the argon flow rate was constant at $150 \mathrm{sccm}$. It can be noted that because of the microwave plasma, for reasons outlined above, the oxygen/argon ratios used here are very low compared to those necessary in conventional sputtering, where ratios of up to 0.5 or higher are necessary to produce $\mathrm{CuO}$. The processes 
were halted once a thickness of 500nm was achieved, controlled by an Inficon quartz crystal controller (and confirmed later by SEM).

\section{Characterisation}

Samples were imaged at various magnifications using a Hitachi $\$ 4100$ field emission scanning electron microscope (SEM). This system has magnification of 40,000 times, a resolution of $1.5 \mathrm{~nm}$, and acceleration voltage for primary electrons of up to $30 \mathrm{kV}$. The crystalline structure of the thin films was determined by X-ray diffractometry (XRD) (Siemens D5000) with CuK a radiation $(40 \mathrm{kV}, 30 \mathrm{~mA})$. The diffraction angle was set between $30^{\circ}$ and $50^{\circ}$ with 1 scan (count) per second at 0.2 increments.

X-ray photoelectron spectroscopy (XPS) was performed on an AXIS Nova (Kratos Analytical, Manchester, UK), utilising a monochromatic AIK $\alpha$ source (1486.6 eV) operated at $225 \mathrm{~W}$ $(15 \mathrm{kV}, 15 \mathrm{~mA})$, and maintaining a base pressure of better than $1 \times 10^{-9} \mathrm{mbar}$. Analysis area was defined by the spectrometer and chosen to be $400 \times 700 \mu \mathrm{m}^{2}$ for all analyses. Survey and high resolution spectra were collected at pass energy of $160 \mathrm{eV}$ and $20 \mathrm{eV}$ respectively. Charge neutralisation was used throughout the analysis. Three points were analysed on each sample surface.

The transmission and reflection spectra of the thin films, deposited on the silica substrates, were measured using an Aquila Instruments' nkd-8000 spectrometer with Pro-Optix software. Samples were all examined in S-polarized light at $10^{\circ}$ angle of incidence, both in transmission and reflection over the 400-1100nm wavelength range.

Data from each sample was analysed by the W Theiss SCOUT programme using the OJL model, named after O'Leary, Johnson, and Lim [36]. The material composition and 
transmittance and reflectance spectra were inputted and the programme simulated similar spectra using optical band gap, Eg, damping constant, $\psi$, refractive index, $n$, extinction coefficient, $k$, and film thickness as fit parameters. This, in effect, is a method to compute the values of these parameters and the degree of correlation of the simulated spectrum to the analysed spectrum is an indicator of the accuracy of those parameters.

Raman scattering measurements were taken using a Thermo Scientific DXR Raman Microscope. Samples were measured using a $100 \mathrm{x}$ objective using $532 \mathrm{~nm} 1.0 \mathrm{~mW}$ laser excitation. Fluorescence corrections and medium cosmic ray thresholds were applied to the data collection.

\section{Results and Discussion}

\subsection{SEM Analysis}

Figure 1 shows the SEM images of the thin layers deposited under oxygen flows of 10, 14, and $17 \mathrm{sccm}$ revealing their thicknesses and smooth surface topography.

$$
\begin{aligned}
& a-10 \mathrm{sccm} \\
& b-14 \mathrm{sccm} \\
& c-17 \mathrm{sccm}
\end{aligned}
$$

Figure 1 SEM of samples under various oxygen flow rates

The SEM images of the thin films confirm the thicknesses and surface topographies. 


\subsection{XRD Analysis}

The XRD results of the samples can be seen in Figure 2.

Figure 2 XRD of samples deposited under various oxygen flows

\section{Under oxygen flow rates of 10 to $16 \mathrm{sccm}$, all thin film comprise mixed phases of $\mathrm{Cu}_{2} \mathrm{O}$ and $\mathrm{Cu}_{4} \mathrm{O}_{3}$. Under oxygen flow rates of $17 \mathrm{scmm}$ or greater, only $\mathrm{CuO}$ is present.}

The location of the spikes in intensity on the XRD plot at the various $2 \theta$ angles of incidence can be related to the material composition and crystalline orientation. The $2 \theta$ angle values for each copper composition were taken from JADE5 PDF tables or Blobaum, et al. [11] and can be seen in Table 1.

\section{Table $12 \theta$ angles for XRD of plasma-assisted DC sputtered copper oxide films}

As noted by Blobaum, et at [11], sputtering of copper in a room temperature oxygen environment produces $\mathrm{Cu}_{4} \mathrm{O}_{3}$ at a similar XRD $2 \theta$ angle to $\mathrm{CuO}$ (111) sputtered in a heated oxygen environment. Therefore, given the low temperature nature of MARS, it is considered likely that the copper oxide phase present at $\sim 38^{\circ}$ is $\mathrm{Cu}_{4} \mathrm{O}_{3}$ and not $\mathrm{CuO}$. Subsequent Raman analysis confirm this.

Consequently, it can be seen that under the various oxygen flows, the composition and orientation of the crystalline structure of the thin layers varies. Also, from the shape of the peaks from the XRD plot, it can be inferred that those with a sharper peak are more crystalline than those with a broader peak, which are more amorphous.

Figure 2 shows a change in behaviour as oxygen flow rates increase. At oxygen flow rates between $11 \mathrm{sccm}$ and $16 \mathrm{sccm}$, there are always multiple phases present of $\mathrm{Cu}_{2} \mathrm{O}$ and $\mathrm{Cu}_{4} \mathrm{O}_{3}$ 
present. However, under oxygen flow rates of $17 \mathrm{sccm}$ or greater, $\mathrm{CuO}$ is the dominant species. It is not surprising that the most oxygen rich phase forms exclusively under the higher oxygen flow rates.

The presence of each phase is noted in Table 2 based on the rate of oxygen flow.

\section{Table 2 Thin film composition at different oxygen flow rates}

\subsection{XPS Analysis}

X-ray Photoelectron Spectroscopy (XPS) was performed to identify the chemical composition of the copper surfaces. Survey spectra for the $10 \mathrm{sccm}$ and $17 \mathrm{sccm}$ samples given in Figure 3a. The only elements detected at the surface were $\mathrm{Cu}, \mathrm{O}$ and $\mathrm{C}$, where the carbon was assumed to be adventitious contamination. The energy scale was calibrated by setting the carbon peak to $284.8 \mathrm{eV}$. Table 3 presents the results of the quantification of chemical composition based on survey spectra for samples from $10-20 \mathrm{sccm}$. Unfortunately, it was not possible to obtain XPS measurements for samples produced under oxygen flow rates of 24,26 , and $28 \mathrm{sccm}$. Upon initial inspection it would appear as though the atomic percentages do not support the presence of the three oxides of copper $\left(\mathrm{Cu}_{2} \mathrm{O}, \mathrm{Cu}_{4} \mathrm{O}_{3}\right.$ and CuO) observed by XRD earlier since the ratio of $\mathrm{Cu}$ to $\mathrm{O}(\mathrm{Cu}: \mathrm{O})$ is around 1:1 for all samples. However XPS is expected to be far more surface sensitive than XRD, with most of the signal (95\%) coming from <8nm depth from the surface. Thus analysis simply based on atomic percentages is not sufficient in this case as it is influenced by any rearrangement of the surface atoms resulting in the formation of surface oxides. Therefore we turn to analysing the high resolution spectra, and referring to reference data for known copper compounds. 


\section{Table 3 Thin film composition at different oxygen flow rates}

Reference $\mathrm{Cu} 2 \mathrm{p}$ and $\mathrm{Cu} L M M$ spectra of three copper materials; $\mathrm{Cu}$ metal, $\mathrm{Cu}_{2} \mathrm{O}\left(\mathrm{Cu}^{1+}\right.$ reference) and $\mathrm{CuO}\left(\mathrm{Cu}^{2+}\right.$ reference) were obtained from the Open Access XPS Reference Database XPSSurfA (Barlow, et al., 2017) and are reproduced in Figure 3b. The three materials can be distinguished from one another when both the $\mathrm{Cu} 2 \mathrm{p}$ and $\mathrm{Cu} L M M$ regions are analysed together. $\mathrm{Cu} 2 \mathrm{p}$ for $\mathrm{Cu}$ metal shows a sharp $2 \mathrm{p}_{3 / 2}$ peak at $932.4 \mathrm{eV}$, with no satellite features. The $\mathrm{Cu}^{1+}$ oxide $\left(\mathrm{Cu}_{2} \mathrm{O}\right)$ has a similar $2 \mathrm{p}_{3 / 2}$ position but also shows a weak satellite feature around $946 \mathrm{eV}$. The $\mathrm{Cu}^{2+}$ oxide $(\mathrm{CuO})$ has a shifted peak position of $933.6 \mathrm{eV}$ and a strong satellite. The peak positions of the three $\mathrm{Cu} L M M$ regions show distinct energies of $918.8 \mathrm{eV}, 916.7 \mathrm{eV}$ and $917.7 \mathrm{eV}$ for the $\mathrm{Cu}^{0}, \mathrm{Cu}^{1+}$ and $\mathrm{Cu}^{2+}$ materials respectively. Thus scans of the Cu2p and $\mathrm{Cu} L M M$ regions were collected on each sample at three points on the surface, and representative spectra are given in Figure $3 c$ and $d$ for the $10 \mathrm{sccm}$ and $17 \mathrm{sccm}$ samples. The $\mathrm{Cu} 2 \mathrm{p}_{3 / 2}$ region of the doublet presented with an intense component at binding energy $932.5 \mathrm{eV}$ along with a less intense shoulder at $934.4 \mathrm{eV}$. The higher binding energy shoulder was taken to be the $\mathrm{Cu}^{2+}$ compound $\mathrm{CuO}$. Present also in the $\mathrm{Cu} 2 \mathrm{p}$ region were a set of satellite features from $940-947 \mathrm{eV}$. These can be identified as satellite features for the $\mathrm{Cu}^{1+}$ and $\mathrm{Cu}^{2+}$ oxidation states, and are not present for metallic copper as seen in the reference data and literature (Espinos, et al., 2002; Platzman, et al., 2008; Biesinger, 2017). Investigation of the $\mathrm{Cu} L M M$ feature (see Figure $3 \mathrm{~d}$ ) for these samples shows an intense peak at $916.7 \mathrm{eV}$ for $10 \mathrm{sccm}$ and $917.4 \mathrm{eV}$ for $17 \mathrm{sccm}$, indicative of a greater amount of $\mathrm{Cu}^{1+}$ and $\mathrm{Cu}^{2+}$ present at each of these surfaces respectively. Thus, the lower binding energy component in the $\mathrm{Cu} 2 \mathrm{p}_{3 / 2}$ region is assumed to be predominantly from $\mathrm{Cu}^{1+}$, and $\mathrm{Cu}_{2} \mathrm{O}$, and two components can be fitted to the $\mathrm{Cu} 2 \mathrm{p}_{3 / 2}$ feature for the $\mathrm{Cu}^{1+}$ and $\mathrm{Cu}^{2+}$ states. 
Figure 3 XPS analysis of the copper surfaces

(a) XPS Survey spectra from the 10sccm and 17sccm samples showing only the presence of

$\mathrm{Cu}$ and $\mathrm{O}$ signals, with a small carbon contaminant. (b) Reference $\mathrm{Cu} 2 \mathrm{p}$ and $\mathrm{Cu}$ LMM spectra for three $\mathrm{Cu}$ compositions; $\mathrm{Cu}$ metal, $\mathrm{CU}_{2} \mathrm{O}$ and $\mathrm{CuO}$ reproduced under $\mathrm{CC} B Y-\mathrm{NC} 4.0$ (Barlow, et al., 2017). (c) and (d) Cu 2p and Cu LMM spectra for the 10sccm and 17sccm samples. The $\mathrm{Cu} 2 p_{3 / 2}$ feature can be fitted with one component for each of the $\mathrm{Cu}^{1+}$ and $\mathrm{Cu}^{2+}$ states. The satellite features observed from 940-947eV further substantiate the presence of these states. The Cu LMM peak energy is at 916.7eV for $10 \mathrm{sccm}$ and $917.4 \mathrm{eV}$ for $17 s c \mathrm{~cm}$ confirming the presence of the $\mathrm{Cu}^{1+}\left(\mathrm{Cu}_{2} \mathrm{O}\right)$ and $\mathrm{Cu}^{2+}(\mathrm{CuO})$ states respectively. The relative ratio of the $\mathrm{Cu} 2 p_{3 / 2}$ components in (c) and the Cu LMM peak energy in (d) is used to monitor the change in oxidation state from $\mathrm{Cu}^{1+}$ to $\mathrm{Cu}^{2+}$ in (e) and (f) as the flow rate is increased from 10 to 20 sccm, with the dominant chemical composition labelled.

With increased flow rate the ratio of the $\mathrm{Cu}^{1+}$ to $\mathrm{Cu}^{2+}$ states could then be monitored via the area of the fitted components, along with the position of the $C u L M M$ peak, as given in Figure $3 e$ and $f$. It was observed that at a flow rate of $12-15 \mathrm{sccm}$ a shift occurs in the dominant oxidation state detected by XPS, with a sharp rise in ratio of $\mathrm{Cu}^{2+}$ occurring beyond this value. This is observed in both the ratio of the fitted components (Figure 3e) and the position of the $L M M$ feature (Figure $3 f$ ). From the analysis of these spectra, and with comparison to the reference data for $\mathrm{Cu}, \mathrm{Cu}_{2} \mathrm{O}$ and $\mathrm{CuO}$ in Fig.3b, we can conclude the chemical composition of the surfaces to be mostly $\mathrm{Cu}_{2} \mathrm{O}$ for $\sim 10-14 \mathrm{SCCM}$, an intermediate oxide of $\mathrm{Cu}_{4} \mathrm{O}_{3}$ (a mixture of $\mathrm{Cu}^{1+}$ and $\mathrm{Cu}^{2+}$ ) for $12-16$ SCCM, and $\mathrm{CuO}$ for $\sim 14-20$ SCCM, and these are labelled in Fig.3e and $f$ as the dominant compositions. This is in excellent agreement with the XRD results presented earlier. 


\subsection{Optical Spectroscopy}

For samples produced under oxygen flows of 10 to $16 \mathrm{sccm}$ and 17 to $28 \mathrm{sccm}$, Figure 4 and Figure 5, respectively, show the optical properties (transmittance, reflectance and absorptance) of the samples across the visible spectrum (400nm to $1100 \mathrm{~nm}$ ).

The Aquila instrument directly measures transmittance and reflectance from the same area of the film. The oscillations observed in these spectra are due to coherent interference of the light reflected from the top and bottom surface of the thin films. It is notable, expected from theory, that these oscillations are dampened greatly in the transmittance spectrum as the extinction factor increases, but are still easily observed in the reflectance spectrum. Given the high reflectance, absorptance, $A$, is calculated using both measured transmittance, $T$, and reflectance, $R$, from Eq 1.

$$
\begin{aligned}
& A=1-T-R \quad A=\text { absorptance } \quad \text { Eq } 1 \\
& T=\text { transmittance } \\
& R=\text { reflectance }
\end{aligned}
$$

This expression ignores incoherent scattering from the surface of the films but this is expected to be low in sputtered films. 


$$
\text { a-transmittance }
$$

$$
b \text { - reflectance }
$$

$$
\text { c-absorptance }
$$

Figure 4 Optical properties of samples deposited under oxygen flow 10-16sccm In general, transmittance decreases and absorptance increases with increased oxygen flow, except for $10 \mathrm{sccm}$ which produces a sample with the lowest transmittance and highest absorptance of all samples (10 to $28 \mathrm{sccm}$ ).

$$
\begin{gathered}
a \text {-transmittance } \\
b \text {-reflectance } \\
c \text {-absorptance }
\end{gathered}
$$

Figure 5 Optical properties of samples deposited under oxygen flow 17-28sccm

In general, all the samples have optical properties within a similar band of $+/-10 \%$. Transmittance values increase from zero at $600 \mathrm{~nm}$ to $50-70 \%$ at $1100 \mathrm{~nm}$. Similarly, absorptance values decrease from $\sim 80 \%$ at $600 \mathrm{~nm}$ to $20-40 \%$ at $1100 \mathrm{~nm}$. Below 750nm, samples deposited under the higher oxygen flows have lower transmittance and higher absorptance values; however, above 750nm, the ordering becomes more random. 
It can be seen that from the plot that the samples with the highest transmittance values are those that were deposited under oxygen flows of 11,12 , and $13 \mathrm{sccm}$. Samples deposited under oxygen flows that were greater or less than this have lower transmittance values.

Concentrating on absorptance values in Figure 4 and Figure 5 , it can be seen that the 10 sccm sample has the highest absorptance, over the entire range of wavelengths from 400 to $1,100 \mathrm{~nm}$. However, this is consistent with an under-oxidised sample containing some metallic $\mathrm{Cu}$ and also, as shown in the XRD, XPS, and Raman results, some $\mathrm{Cu}_{2} \mathrm{O}$. The presence of metallic $\mathrm{Cu}$ would render any such thin film not useful for semi-conductor applications, such as a solar cell; however, no other characterisation technique indicated the presence of metallic $\mathrm{Cu}$. From 11 to $13 \mathrm{sccm}$, the films have high absorptance $(>0.2)$ only in the range 400 to $700 \mathrm{~nm}$ and from 15 to $28 \mathrm{sccm}$ there is considerable absorptance out to $1,100 \mathrm{~nm}$. It is known from the literature [41] that the extinction coefficient of $\mathrm{Cu}_{2} \mathrm{O}$ is lower than that of $\mathrm{CuO}$ above $600 \mathrm{~nm}$ and so these results are consistent with the increasing oxidation of the films, progressing through $\mathrm{Cu}_{2} \mathrm{O}, \mathrm{Cu}_{2} \mathrm{O} / \mathrm{Cu}_{4} \mathrm{O}_{3}, \mathrm{Cu}_{4} \mathrm{O}_{3} / \mathrm{CuO}$, and $\mathrm{CuO}$ as the oxygen flow rate increases from $11 \mathrm{sccm}$ to $28 \mathrm{sccm}$.

Although of little practical use in the rather complicated field of nano-structured thin films with variable chemical composition, being only a single number that indicates the onset of optical absorptance, it is nevertheless usual to determine the so-called optical band gap from measurements of transmittance.

The various compositions of $\mathrm{Cu}_{x} \mathrm{O}_{y}$ are known to have various band gap ranges [42]. For $\mathrm{Cu}_{2} \mathrm{O}$ it is between 2.20 and $2.90 \mathrm{eV}$ [42], for $\mathrm{Cu}_{4} \mathrm{O}_{3}$ it is between 1.34 and 2.47eV [15], and for CuO it is between 1.21 and $2.20 \mathrm{eV}$ [42]. These results are highly variable, varying with the composition, and just as importantly, varying with nano-structure as band gap is known 
to increase with diminishing grain size. In, for example, solar cell applications, the most important consideration is how absorption varies over the solar spectrum, so the single value of band gap is of little consequence in practice.

The optical band gap, Eg, damping constant, $\gamma$, refractive index, $n$, extinction coefficient, $k$, and film thicknesses for each sample were calculated by fitting the experimental data with the OJL model using the commercially available SCOUT package from W Theiss Software [43]. Examples of measured and fitted spectra are shown in Figure 6, with the measured spectrum shown in red and the fitted spectrum shown in blue in each case.

Table 4 shows the derived parameters (at 550nm wavelength) and the estimated thickness for each film using both software packages. The thicknesses as measured from SEM crosssections.

The thin films being analysed are nano-structured and polycrystalline. In such material, the exponential decay of the valance band's and conduction band's tails need to be considered. The OJL model incorporates a parameter to account for this - damping constant, $\gamma$.

Table 4 Optical properties simulation parameters with SEM thickness data

$a-$ Transmittance and reflectance for oxygen flow rate of $11 \mathrm{sccm}$

b - Transmittance and reflectance for oxygen flow rate of $14 \mathrm{sccm}$

c - Transmittance and reflectance for oxygen flow rate of $17 \mathrm{sccm}$

Figure 6 Example simulated optical spectra by OJL model 
Measured spectra are shown in red and fitted spectra are shown in blue.

The optical band gap values derived by the OJL model for each sample are in accordance with the optical band gap values for the phases determined to be present by XRD, XPS, and Raman. That is, at lower oxygen flows, the presence of $\mathrm{Cu}_{2} \mathrm{O}$ and $\mathrm{Cu}_{4} \mathrm{O}_{3}$ was found to be dominant. The expected band gap values for these phases is $2.2-2.9 \mathrm{eV}$ and $1.34-2.47 \mathrm{eV}$, respectively. At higher oxygen flows, the presence of $\mathrm{CuO}$ was found to be dominant. The expected band gap value for this phase is $1.21-2.2 \mathrm{eV}$. The optical band gap values determined by the $\mathrm{OJL}$ model appear to track the transition from $\mathrm{Cu}_{2} \mathrm{O}$ to $\mathrm{CuO}$ being dominant as oxygen flows increase.

Samples produced with an oxygen flow rate of $10 \mathrm{sccm}$ are an exception to this trend; however, as mentioned previously, this sample contains some Cu metal and so the spectra cannot be fitted by the OJL model.

Similarly, the OJL model confirms that the extinction coefficient of $\mathrm{Cu}_{2} \mathrm{O}$ dominant films is lower than that of $\mathrm{CuO}$ dominant films, as expected. However, the extinction coefficient of the $10 \mathrm{sccm}$ sample is anomalously high; again, this is likely due to the presence of metal $\mathrm{Cu}$.

The thicknesses derived by OJL model and SEM are broadly in agreement with each other.

\subsection{Raman Measurements}

Initial Raman measurements showed that samples grown in the MARS system formed $\mathrm{Cu}_{2} \mathrm{O}$ as well as $\mathrm{Cu}_{4} \mathrm{O}_{3}$ in higher $\mathrm{O}_{2}$ processed samples. The Raman results are shown in Figure 7 for oxygen flows of 10 to $28 \mathrm{sccm}$. By comparison with Table 5 , which notes the various copper oxide Raman Shift values, it can be seen that at $10 \mathrm{sccm}, \mathrm{Cu}_{2} \mathrm{O}$ is the only phase 
present; between $11 \mathrm{sccm}$ and $16 \mathrm{sccm}$, mixed phases of $\mathrm{Cu}_{2} \mathrm{O}$ and $\mathrm{Cu}_{4} \mathrm{O}_{3}$ are present; between $17 \mathrm{sccm}$ and $20 \mathrm{sccm}, \mathrm{Cu}_{4} \mathrm{O}_{3}$ is the only phase present; at $24 \mathrm{sccm}$, mixed phases of $\mathrm{Cu}_{4} \mathrm{O}_{3}$ and $\mathrm{CuO}$ are present; and at $26 \mathrm{sccm}$ and greater, $\mathrm{CuO}$ is the only phase present.

Table 5 Raman shifts of $\mathrm{Cu}_{x} \mathrm{O}_{y}[44,15]$

The presence of the various forms of copper oxide are summarised in Table 6.

$a-10-16 s c c m$

$b-17-20 s c c m$

Figure 7 Raman measurements of MARS thin films at various oxygen flows

The peaks indicate the presence of $\mathrm{Cu}_{2} \mathrm{O}$ for thin films produced under oxygen flows between $10 \mathrm{sccm}$ and $16 \mathrm{sccm}$, the presence of $\mathrm{Cu}_{4} \mathrm{O}_{3}$ under oxygen flows between $11 \mathrm{sccm}$ and $24 \mathrm{sccm}$, and the presence of CuO under oxygen flows between $24 \mathrm{sccm}$ and $28 \mathrm{sccm}$.

Table 6 Interpretation of copper oxide content based on Raman observations

It can be noted that there are differences between the XRD results and Raman results for the $17 \mathrm{sccm}$ to $24 \mathrm{sccm}$ samples. For $17 \mathrm{sccm}$ to $20 \mathrm{sccm}, \mathrm{XRD}$ detects the presence of $\mathrm{CuO}$, whereas Raman detects the presence of $\mathrm{Cu}_{4} \mathrm{O}_{3}$. For $24 \mathrm{sccm}, \mathrm{XRD}$ detects the presence of $\mathrm{CuO}$, whereas Raman detects the presence of a mixture $\mathrm{Cu}_{4} \mathrm{O}_{3}$ and $\mathrm{CuO}$. However, the XRD and Raman techniques probe fundamentally different physical properties. XRD derives information from crystal plains and is therefore sensitive to the crystallinity of the sample, whereas Raman is sensitive to the polarizability of molecular bonds, which can identify amorphous phases more so than XRD. Therefore, in mixtures where different crystal 
orientations will affect XRD intensity, Raman will be able to identify different phases where XRD does not, ie, in the $24 \mathrm{sccm}$ sample. Thus, XRD can determine structural information of the bulk of the film, whereas Raman measurements provide information of the film surface (that may be of different composition to the bulk) as noted in other research that "Raman spectroscopy, unlike XRD, can only get the structure information from the top layer of the thin film" [45].

\section{Conclusions}

It is demonstrated that the sputtered films develop through $\mathrm{CuO}, \mathrm{Cu}_{4} \mathrm{O}_{3}$ and $\mathrm{Cu}_{2} \mathrm{O}$ mixed phases as oxygen flow rate is increased and can be successfully and reproducibly grown at room temperature. A pure form of $\mathrm{Cu}_{2} \mathrm{O}$ is only produced under an oxygen flow rate of 10sccm; however, this may be contaminated by Cu metal.

The results indicate that $\mathrm{Cu}_{4} \mathrm{O}_{3}$ can be reliably produced by MARS at oxygen flow rates between $11 \mathrm{sccm}$ and $16 \mathrm{sccm}$, and possibly at higher oxygen flow rates as well.

For the production of solar cells, $\mathrm{Cu}_{2} \mathrm{O}$ thin films are preferable due to the better optical and electrical properties over the other phases of copper oxide.

It is concluded that careful control of the oxygen flow rate (and therefore partial pressure of oxygen) is critically important in the production of particular stoichiometries of copper oxides. It has also been shown that detailed characterisation of the sputtered films is possible with the aid of XPS, XRD, optical and Raman measurements. The OJL model was used to determine the E gap and optical properties and confirmed by the other methods. In particular, given that many of the earlier papers to be found in the literature ignored the 
possibility of the formation of $\mathrm{Cu}_{4} \mathrm{O}_{3}$, their findings will possibly require some reconsideration.

\section{Acknowledgments}

XPS data were acquired at the National EPSRC XPS User's Service at Newcastle University, an EPSRC Mid-Range Facility. This work incorporates data from the Victorian node of the Australian National Fabrication Facility (ANFF), a company established under the National Collaborative Research Infrastructure Strategy to provide nano and microfabrication facilities for researchers in Australia, through the La Trobe University Centre for Materials and Surface Science. Data are reproduced under a Creative Commons licence (CC BY-NC 4.0 International).

\section{References}

[1] S. S. Jeong, A. Mittiga, E. Salza, A. Masci and S. Passerini, "Electrodeposited ZnO/Cu2O heterojunction solar cells," Electrochimica Acta, vol. 53, pp. 2226-2231, 2008.

[2] F. Li, R. Waddingham, W. Milne, A. Flewitt and S. Speakman, "Low temperature $(<100$ ${ }^{\circ} \mathrm{C}$ ) deposited P-type cuprous oxide thin films: Importance," Thin Solid Films, vol. 520 , p. 1278-1284, 2011.

[3] A. Parretta, M. K. Jayaraj, A. Di Nocera, S. Loreti, L. Quercia and A. Agati, "Electrical and optical properties of copper oxide films prepared by reactive RF magnetron sputtering," Physica Status Solida A, vol. 155, pp. 399-404, 1996.

[4] F. Oba, F. Ernst, Y. Yu, R. Liu, H. M. Kothari and J. A. Switxer, "Epitaxial growth of cuprous oxide electrodeposited onto semiconductor and metal substrates," Journal of the American Ceramic Society, vol. 88, no. 2, pp. 253-270, 2005.

[5] K. Akimoto, S. Ishizuka, M. Yanagita, Y. Nawa, G. K. Paul and T. Sakurai, "Thin film deposition of Cu2O and application for solar cells," Solar Energy, vol. 80, no. 6, pp. 715- 
722, 2006.

[6] P. J. M. Isherwood, "Copper zinc oxide: Investigation into a p-type mixed metal oxide system," Vacuum, vol. 139, pp. 173-177, 2017.

[7] T. J. Richardson, J. L. Slack and M. D. Rubin, "Electrochromism of copper oxide thin films," in Presented at 4th International Meeting on Electrochromism, Uppsala, Sweden, 2000.

[8] B. Balamurugan and B. R. Mehta, "Optical and structural properties of nanocrystalline copper oxide thin films prepared by activated reactive evaporation," Thin solid films, vol. 96, no. 1, pp. 90-96, 2001.

[9] A. A. Ogwu, E. Bouquerel, O. Ademosu, S. Moh, E. Crossan and F. Placido, "The influence of RF power and oxygen flow rate during deposition on the optical transmittance of copper oxide thin films prepared by reactive magnetron sputtering," Journal of Physics D: Applied Physics, vol. 38, pp. 266-271, 2005a.

[10] V. F. Drobny and D. L. Pulfrey, "Properties of reactively-sputtered Copper Oxide thin films," Thin Solid Films, vol. 61, pp. 89-98, 1979.

[11] K. J. Blobaum, D. Van Heerden, A. J. Wagner, D. H. Fairbrother and T. P. Weihs, "Sputter-deposition and characterization of paramelaconite," Journal of Materials Research, vol. 18, no. 7, pp. 1535-1542, 2003.

[12] J. F. Pierson, A. Thobor-Keck and A. Billard, "Cuprite, paramelaconite and tenorite films deposited by reactive magnetron sputtering," Applied Surface Science, vol. 210, no. 3-4, pp. 359-367, 2003.

[13] J. Medina-Valtierra, C. Frausto-Reyes, G. Camarillo-Martínez and J. A. Ramírez-Ortiz, "Complete oxidation of isopropanol over $\mathrm{Cu} 4 \mathrm{O} 3$ (paramelaconite) coating deposited on fiberglass by CVD," Applied Catalysis A: General, vol. 356, no. 1, pp. 36-42, 2009.

[14] D. Reppin, A. Polity, B. K. Meyer and S. Shokhovets, "Optical and electrical properties of Cu2O, Cu4O3 and CuO," In MRS Proceedings, vol. 1494, pp. 165-169. Cambridge University Press, 2013.

[15] A. S. Zoolfakar, R. A. Rani, A. J. Morfa, A. P. O'Mullane and K. Kalantar-Zadeh, "Nanostructured copper oxide semiconductors: a prespective on materials, senthesis methods and applications," Journal of materials Chemistry C, vol. 2, no. 27, pp. 52475270, 2014.

[16] A. A. Ogwu, T. H. Darma and E. Bouquerel, "Electrical resistivity of copper oxide thin 
films prepared by reactive magnetron sputtering," Journal of Achievements in Materials and Manufacturing Engineering, vol. 24, no. 1, pp. 172-177, 2007.

[17] B. C. Castle, "Memristive Properties of Thin Film Cuprous Oxide," MSc thesis, Air University, Wright-Patterson Air Force Base, Ohio, 2011.

[18] L. Chua, "Linear transformation converter and its application to the synthesis of nonlinear networks," IEEE Transactions on Circuit Theory, vol. 17, no. 4, pp. 584-594, 1970.

[19] K. Fujimoto, T. Oku, T. Akiyama and A. Suzuki, "Fabrication and characterization of copper oxide-zinc oxide solar cells prepared by electrodeposition," Journal of Physics: Conference Series, vol. 433, no. 1, pp. 12-24, 2013.

[20] T. K. S. Wong, S. Zhuk, S. Masudy-Panah and G. K. Dalapati, "Current status and future prospects of copper oxide heterojunction solar cells," Materials, vol. 9, no. 4, p. 271, 2016.

[21] J. J. Loferski, "Theoretical considerations governing the choice of the optimum semiconductor for photovoltaic solar energy conversion," Jouurnal of Applied Physics, vol. 27, no. 7, pp. 777-784, 1956.

[22] L. C. Olsen, R. C. Bohara and M. W. Urie, "Explanation for low-efficiency Cu2O Schottky-barrier solar cells," Applied Physics Letters, vol. 34, no. 1, p. 47, 1979.

[23] T. Minami, Y. Nishi and T. Miyata, "Heterojunction solar cell with $6 \%$ efficiency based on an n-type aluminum-gallium-oxide thin film and p-type sodium-doped Cu2O sheet," Applied Physics Express, vol. 8, no. 2, 2015.

[24] K. Ozawa, Y. Oba and K. Edamota, "Formation and characterization of the Cu2O overlayer on Zn(0001)," Journal of science, vol. 603, no. 13, pp. 2163-2170, 2009.

[25] A. A. Ogwu, E. Bouquerel, O. Ademosu, S. Moh, E. Crossan and F. Placido, "An investigation of the surface energy and optical transmittance of copper oxide thin films by reactive magnetron sputtering," Acta Materialia, vol. 53, pp. 5151-5159, 2005b.

[26] S. C. Ray, "Preparation of copper oxide thin film by the sol-gel-like dip technique and study of their structural and optical properties," Solar energy materials and solar cells, vol. 68, pp. 307-312, 2001.

[27] G. N. Papadimitropoulos, N. Vourdas, E. Vamvakas and D. Davazoglou, "Optical and structural properties of copper oxide thin films grown byoxidation of metal layers," Thin Solid Films, vol. 515, p. 2428-2432, 2006. 
[28] R. Kita, T. Hase, R. Itti, M. Sasaki, T. Morishita and S. Tanaka, "Synthesis of cupric oxide films using mass-separated low-energy beam," Applied Physica Letters, vol. 60, pp. 2624-2630, 1992.

[29] F. K. Mugwang, P. K. Karimi, P. K. Njoroge, O. Omayio and S. M. Waita, "Optical characterisation of copper oxide films prepared by reactive DC magnetron sputtering for solar cell applications," International Journal of Thin Films Science and Technology, vol. 2, no. 1, pp. 15-24, 2013.

[30] S. Moh, Microwave Assisted Sputtered Coatings, PhD Thesis, University of the West of Scotland, Paisley, Scotland, UK, 2012.

[31] Y. Alajlani, F. Placido, D. Gibson, H. M. Chu, S. Song, L. Porteous and S. Moh, "Nanostructured ZnO films prepared by hydro-thermal chemical deposition and microwave-activated reactive sputtering," in 57th Annual Technical Conference Proceedings, Santa Clara, CA, 2015.

[32] M. Mazur, D. Wojcieszak, J. Domaradzki, D. Kaczmarek, S. Song and F. Placido, "TiO2/SiO2 multilayer as an antireflective and protective coating deposited," Opto electronics review, vol. 21, no. 2, p. 233-238, 2013.

[33] Z. Gou and F. Placido, "Aluminum oxynitride rugate filters grown by reactive rf sputtering," Proc SPIE, vol. 4086, pp. 791-794, 2000.

[34] F. Placido, Z. Gou and C. Rebecchi, " Microwave-assisted reactive sputtering of aluminum oxynitrides," Proc SPIE, vol. 4086, pp. 376-381, 2000.

[35] P. J. Kelly and R. D. Arnell, "Magnetron sputtering: a review of recent developments and applications," Vacuum, vol. 56, no. 3, pp. 159-172, 2000.

[36] S. K. O'Leary, S. R. Johnson and P. K. Lim, "The relationship between the distribution of electronic states and the optical absorption spectrum of an amorphous semiconductor: An empirical analysis," Journal of Applied Physics, vol. 82, no. 7, pp. 3334-3340, 1997.

[37] A. J. Barlow, A. J. McDonald, P. J. Pigram and R. T. Jones, "XPSSurfA - An Online Collaborative Surface Analysis (Data reproduced under Creative Commons Attribution Non Commercial 4.0 International. Full terms at: https://creativecommons.org/licenses/by-nc/4.0/)," 2017. [Online]. Available: https://cmsshub.latrobe.edu.au/xpsdatabase. [Accessed 10 July 2017].

[38] J. P. Espinos, J. Morales, A. Barranco, A. Caballero, J. P. Holgado and A. R. GonzalezElipe, "Interface effects for $\mathrm{Cu}, \mathrm{CuO}$, and $\mathrm{Cu} 2 \mathrm{O}$ deposited on $\mathrm{SiO} 2$ and $\mathrm{ZrO} 2$. XPS determination of the valence state of copper in $\mathrm{Cu} / \mathrm{SiO} 2$ and $\mathrm{Cu} / \mathrm{ZrO} 2$ catalysts," The 
Journal of Physical Chemistry B, vol. 106, no. 27, pp. 6921-6929, 2002.

[39] I. Platzman, R. Brener, H. Haick and R. Tannenbaum, "Oxidation of polycrystalline copper thin films at ambient conditions," The Journal of Physical Chemistry C, vol. 112, no. 4, pp. 1101-1108, 2008.

[40] M. C. Biesinger, "Advanced analysis of copper X-ray photoelectron spectra," Surface and Interface Analysis, Early View (Online), DOI: 10.1002/sia.6239, 2017.

[41] C. G. Ribbing and A. Roos, "Part II: Critiques, Subpart 3: Insulators, Copper Oxides (Cu2O, CuO)," in Handbook of Optical Constants of Solids II, E. D. Palik, Ed., London, UK, Academic Press, 1997, pp. 875-882.

[42] F. K. Mugwang'a, P. K. Karimi, W. K. Njoroge, O. Omayio and S. M. Waita, "Optical charactrization of copeer oxide thin films prepared by reactive dc magnetron sputtring for solar cell applications," Internationl Journal of Thin Films Sciences and Technology, vol. 2, no. 1, pp. 15-24, 2013.

[43] W Theiss, "OJL interband transition model for amorphous materials - a brief tutorial," [Online]. Available: http://www.mtheiss.com/ojlmodel.htm. [Accessed 13 February 2017].

[44] L. Debbichi, M. C. Marco, D. Lucas, F. J. Pierson and P. Krüger, "Vibrational properties of $\mathrm{CuO}$ and $\mathrm{Cu} 4 \mathrm{O} 3$ from first-principles calculations, and Raman and Infrared Spectroscopy," The Journal of Physical Chemistry C, vol. 116, pp. 10232-10237, 2012.

[45] Y. S. Gong, C. Lee and C. K. Yang, "Atomic force microscopy and Raman spectroscopy studies on the oxidation of Cu," Journal of Applied Physics, vol. 77, p. 5422, 1995. 